\title{
O COTIDIANO ESCOLAR DO COORDENADOR PEDAGÓGICO: DIVERSIDADES, TENSÕES E POSSIBILIDADES
}

\author{
Jane Cordeiro de Oliveira ${ }^{1}$
}

\begin{abstract}
Resumo: O texto é parte de duas pesquisas qualitativas que tratam do cotidiano do coordenador pedagógico e dos desafios enfrentados no decorrer de seu trabalho. Questões: o que é entendido como cotidiano escolar no entendimento do coordenador pedagógico? Como o coordenador pedagógico trabalha, de acordo com a sua atribuição, no cotidiano escolar? Quais são os desafios que o coordenador encontra em seu trabalho cotidiano?, orientam o recurso de alcance do objetivo que é apresentar diversidades, tensões e possibilidades existentes no cotidiano do coordenador pedagógico, analisando os depoimentos dos sujeitos no exercício de seus cotidianos. $\mathrm{O}$ coordenador enfrenta desafios vindos do cotidiano tendo em vista a falta de profissionais e ele necessita assumir tarefas que não são inerentes a sua atribuição. $\mathrm{O}$ coordenador, mesmo frente às dificuldades vindas da infraestrutura, tenta manter a organização escolar.
\end{abstract}

Palavras-chave: Cotidiano; Coordenador pedagógico; Infraestrutura da escola.

\section{THE PEDAGOGICAL COORDINATOR'S DAILY SCHOOL: DIVERSITIES, TENSIONS AND POSSIBILITIES}

\begin{abstract}
This paper is part of two qualitative researches that deal with the routine of the pedagogical coordinator and the challenges faced in the course of his or her work. Questions: How is the school routine understood in the interpretation of the pedagogical coordinator? How does the pedagogical coordinator work, according to his or her attributions, in school routine? Which are the challenges that the coordinator faces in his or her daily job? Objective: Present the existing diversities, tensions and possibilities in the routine of the pedagogical coordinator, through the analysis of the subjects' statements in the exercise of their routine. The coordinator faces challenges come from daily routine in view of the lack of professionals and he or she needs to assume tasks that are not related to his or her assignment. The coordinator, even in the face of difficulties, comes from infrastructure problems, try to keep school organization.
\end{abstract}

Keywords: Routine; Pedagogic coordinator; School's infrastructure.

\footnotetext{
${ }^{1}$ Doutora em Educação Brasileira pela PUC-Rio e docente da Rede de Ensino Fundamental Público da Cidade do Rio de Janeiro. Email: janecoliveira@yahoo.com.br

Momento: diálogos em educação, E-ISSN 2316-3100, v. 26, n. 1, p. 143-160, jan./jun. 2017
} 


\section{INTRODUÇÃO}

Este artigo traz uma análise do cotidiano do coordenador pedagógico que atua nas escolas públicas municipais da Cidade do Rio de Janeiro. O coordenador faz parte da equipe de gestão escolar, juntamente com o diretor e o diretor adjunto, inserido num espaço burocraticamente organizado em que estão presentes diversas práticas cotidianas de cunhos administrativo e pedagógico, relacionadas ao funcionamento do sistema escolar. Há muitos estudos referindo-se ao cotidiano de professores e alunos, porém, trazemos neste texto, o cotidiano do coordenador pedagógico como uma questão relevante a ser estudada e observada. Pais considera que o cotidiano é uma rotina onde prevalecem determinadas formas de conduta sustentadas por uma "segurança ontológica" de que a realidade é o que ela aparenta ser. Por isso, buscamos no autor a definição de cotidiano como um conjunto de "ritualidades" que se constituem ao se descortinar os meandros da vida social, sendo comparado como uma "imagem latente de uma película fotográfica" (PAIS, 2003, p.31). Utilizaremos o termo "rotina" como categoria para definição das "ritualidades" dos coordenadores pedagógicos no decorrer da análise de suas narrativas no tempo e espaço da escola. Este termo está presente nas falas dos coordenadores entrevistados. Portanto, como membro da equipe gestora da escola, o coordenador pedagógico possui atribuições específicas que são inerentes ao desempenho de seu trabalho.

A função "coordenador pedagógico" foi instituída em 1998, através da Lei Municipal 2619 (RIO DE JANEIRO, 1998a), para que este docente atuasse junto ao diretor e ao diretoradjunto na tarefa de organizar o "fazer" pedagógico da escola. Segundo essa legislação, o coordenador atua na organização e na construção do Projeto Político Pedagógico (PPP), atendendo as indicações da Lei 9394 (BRASIL, 1996) às escolas para que estas venham formular suas propostas pedagógicas dentro dos princípios de autonomia e democracia presentes na referida lei. Com isso, ele passa a ter suas atribuições definidas pela Circular SME $n^{\circ} 37$ que trata das tarefas cotidianas de responsabilidade específica do coordenador pedagógico:

- Assessorar tecnicamente a construção do Projeto Político Pedagógico da escola em todas as suas etapas; elaboração, implementação e avaliação;

- Promover, junto com a Direção, a integração dos professores das diferentes disciplinas e segmentos, garantindo a interdisciplinaridade e a articulação entre as diferentes séries e níveis da Educação Básica; 
- Coordenar, organizar e participar, junto com a Direção, dos Centros de Estudos ${ }^{2}$, Conselhos de Classe e outras atividades promovidas pela unidade escolar;

- Conhecer e participar da elaboração das normas que regulam o gerenciamento da unidade escolar;

- Assessorar tecnicamente a Direção na elaboração dos horários da unidade escolar possibilitando melhor atendimento ao aluno e garantindo a concretização do processo ensino-aprendizagem, de acordo com a legislação vigente (RIO DE JANEIRO, 1998b, p.8-9).

As atribuições discriminadas no extrato anterior revelam que o coordenador pedagógico é responsável; pela organização da escola junto com a direção e pela promoção de atividades que possam servir como instrumentos para o desenvolvimento da aprendizagem dos alunos. Ele também atua junto ao diretor em tarefas que tratam da organização da escola a fim de "beneficiar o atendimento ao aluno" (RIO DE JANEIRO,1998b, p.8-9).

Podemos perceber que o coordenador pedagógico, em seu cotidiano de trabalho, realiza diversas atividades presentes em diferentes frentes de atuação. André (2003) afirma que, ao realizarmos estudos em escolas, devemos observar três dimensões: "organizacional, pedagógica e sociopolítica/cultural" essas definem todas as ações realizadas no espaço da escola pelos profissionais que nela trabalham: professores, gestores e funcionários.

Apresentamos o coordenador pedagógico como sujeito e protagonista de nossas pesquisas, e, portanto, levantamos os seguintes questionamentos: $\mathrm{O}$ que é entendido como cotidiano escolar para o coordenador pedagógico? Quais são os desafios que o coordenador encontra em seu trabalho no dia a dia da escola? Orientados pelos questionamentos, o nosso objetivo é apresentar as diversidades, as tensões e as possibilidades existentes no cotidiano de trabalho do coordenador pedagógico no espaço da escola, analisando os depoimentos dos sujeitos enquanto protagonistas no exercício de seu fazer cotidiano.

O cotidiano escolar, segundo Alves (2003), se caracteriza como uma rede de subjetividades de múltiplos processos onde este está inserido numa relação com a cultura no espaço escolar. Sacristán (1999) considera que as práticas organizadas e relacionadas ao funcionamento da escola, o trabalho com os professores, a divisão de tempo e do espaço escolar, abrangem o coletivo da escola, envolvendo as práticas pedagógicas direcionadas aos relacionamentos sociais ligados à comunicação interpessoal.

\footnotetext{
${ }^{2}$ Centro de Estudos: reuniões periódicas que os coordenadores pedagógicos promovem no espaço da escola com os professores para efetuarem as seguintes atividades: fomentar a formação continuada, acompanhar o planejamento dos docentes, desenvolver e atualizar o projeto político pedagógico.

Momento: diálogos em educação, E-ISSN 2316-3100, v. 26, n. 1, p. 143-160, jan./jun. 2017
} 
O cotidiano, na visão de Pais (2003), é definido como os caminhos que denunciam os múltiplos meandros da vida social dos sujeitos. Neste caso, o autor considera que o cotidiano pode ser considerado como a "rotina, expressando o hábito de fazer as coisas sempre da mesma maneira" concluindo que a rotina pode ser considerada como "um elemento básico das atividades sociais" (PAIS, 2003, p. 28, 29). Portanto, o cotidiano escolar é visto como um conjunto de "ritos" que são cumpridos no dia a dia de gestores, professores, alunos e funcionários obedecendo a contextos sociais e culturais já estabelecidos, que definem os lugares socioculturais e as tarefas que são de responsabilidade de cada um daqueles que frequentam o mesmo espaço escolar. No caso dos coordenadores pedagógicos, seus ritos são definidos pelas suas atribuições e pelas tarefas desempenhadas; e isso visando à organização escolar.

\section{PERCURSOS METODOLÓGICOS}

Os dados que apresentamos neste estudo foram resultantes de duas pesquisas qualitativas, realizadas em 2009 e 2015, onde o instrumento de coleta de dados utilizado foi a entrevista semiestruturada. $\mathrm{O}$ foco das questões que levamos ao campo versou em torno das ações do coordenador pedagógico no percurso de seu cotidiano. Em nossa primeira pesquisa, realizada em 2009, entrevistamos doze (12) coordenadores pedagógicos em escolas localizadas nos bairros da Taquara, Barra da Tijuca, Largo do Tanque, Praça Seca, localizados na zona oeste da Cidade do Rio de Janeiro.

Em relação ao perfil das escolas onde trabalham os coordenadores entrevistados constatamos que, sete (7) atendem somente os primeiros anos do ensino fundamental (Educação Infantil ao $5^{\circ}$ ano), duas (2) atendem a todo o ensino fundamental, e três (3) atendem aos anos finais do ensino fundamental $\left(6^{\circ}\right.$ aos $9^{\circ}$ anos $)$ e à Educação de Jovens e Adultos (EJA) noturno. Entrevistamos onze (11) coordenadoras e um (01) coordenador. Todos são formados no ensino superior, com cursos voltados para a Educação. Todos possuíam, na época da realização da pesquisa em campo, larga experiência docente variando entre quatorze (14) e trinta e um (31) anos, e tempo de exercício da função variando entre dois (2) e dez (10) anos. A faixa etária dos entrevistados era delimitada em trinta e quatro (34) e cinquenta e um (51) anos. 
$\mathrm{Na}$ segunda pesquisa, realizada em 2015, entrevistamos dezoito (18) coordenadores pedagógicos atuantes em escolas públicas municipais que atendem, especificamente, aos primeiros cinco anos do ensino fundamental (Educação Infantil ao $5^{\circ}$ ano), localizadas nos bairros da Taquara, Curicica, Praça Seca, Vargem Grande, Copacabana, Lagoa, Vidigal, Tijuca e Rio Comprido, nas zonas oeste, sul e norte da Cidade do Rio de Janeiro. As escolas selecionadas para visitação de campo foram aquelas que obtiveram um bom desempenho no Índice de Desenvolvimento da Educação Básica (IDEB) em 2011, com indicadores iguais ou acima de $5,4^{3}$ (BRASIL, 2012).

$\mathrm{Na}$ pesquisa de 2015, todas as coordenadoras entrevistadas são do sexo feminino e possuem formação universitária. As idades variam entre trinta e três (33) e sessenta e dois (62) anos, com larga experiência como professoras e tempo de docência variando entre sete (7) e quarenta e um (41) anos. O tempo de trabalho na coordenação versa entre um mês e dez (10) anos.

Duarte (2004, p. 215) considera a entrevista como um instrumento fundamental para "mapear práticas, crenças, valores e sistemas classificatórios de universos sociais específicos". O que é reiterado por Oliveira, Fonseca e Santos (2010, p. 38-39) que afirmam que a entrevista é uma abordagem metodológica "relevante para obtenção de dados de caráter subjetivo", sendo considerada como "um instrumento metodológico dialógico e interativo que possibilita a obtenção de dados" tais como: "imaginários, sentimentos, valores, emoções", integrantes das dimensões "social, histórica e cultural".

Com base nestes critérios, percebemos que a entrevista pode ser considerada como o registro do "cotidiano subjetivo", onde o sujeito entrevistado tem a possibilidade de recorrer às suas memórias e lembranças permeadas por suas práticas e experiências de vida. Nosso campo de observação passa a ser captado pelos 'olhos do outro' e podemos visualizar o cotidiano escolar sob a ótica do entrevistado. As narrativas podem ser consideradas 'retratos de cotidiano', pois os registros de áudio, passados por processo de transcrição, são transformados em texto, e a partir da análise de conteúdo, podem revelar ao pesquisador uma percepção pessoal do entrevistado, de suas vivências no dia a dia de seu trabalho no espaço

\footnotetext{
3 Índice que corresponde à média obtida pelas escolas públicas municipais da Cidade do Rio de Janeiro, em 2011, nas avaliações do $5^{\circ}$ ano da Prova Brasil.
} 
escolar. A abordagem da análise de conteúdo busca "explicar e sistematizar o conteúdo da mensagem e o significado mediante deduções lógicas e justificadas, tendo como referência o contexto da mensagem e os efeitos dessa mensagem" (OLIVEIRA, ENS, FREIRE ANDRADE, MUSSIS, 2003, p.4).

No percurso de realização das entrevistas nas duas pesquisas realizadas com os coordenadores pedagógicos, obedecemos ao rigor da elaboração das questões a serem abordadas. Em ambas as pesquisas, primeiramente, testamos o instrumento de coleta de dados em campo. Na pesquisa de 2009 escolhemos dois sujeitos coordenadores que não participaram da pesquisa, mas, através da análise da conversa com os sujeitos as informações coletadas serviram para identificarmos as falhas do instrumento e podermos corrigi-las. $\mathrm{Na}$ pesquisa de 2015, escolhemos três sujeitos coordenadores não participantes dos dados da pesquisa, tendo a finalidade de atualizar e contextualizar o instrumento para a entrada em campo. Nosso cuidado tem o objetivo de que os entrevistados possam nos fornecer, através da aplicação do instrumento testado, "dados empíricos ricos e densos" (DUARTE, 2004, p.216) que serviram de fontes para identificarmos as cotidianidades dos coordenadores pesquisados.

Buscamos contato prévio com os coordenadores por telefone e assim, combinamos os encontros e as regras de realização das entrevistas de forma que pudéssemos utilizar e publicar os dados resultantes de nossos estudos. Os participantes de ambas as pesquisas assinaram o Termo de Consentimento Livre e Esclarecido (TCLE), após estas serem aprovadas pelo comitê de ética da Pontifícia Universidade Católica do Rio de Janeiro (PUCRio) e da autorização da Secretaria Municipal de Educação (SME).

Todos os encontros com os coordenadores pedagógicos entrevistados foram feitos em seus respectivos locais de trabalho. Nosso objetivo também era observar situações que surgiam no momento da realização da entrevista. Por isso, além de gravar as falas dos sujeitos, fizemos registros escritos em caderno de campo, resultado das observações feitas pela pesquisadora a respeito da organização da escola, descrição do espaço físico assim como situações que ocorriam no decorrer da entrevista.

\section{O COTIDIANO DOS COORDENADORES PEDAGÓGICOS}

O cotidiano do coordenador pedagógico é considerado como o conjunto de atividades que ele planeja e executa dentro do percurso do exercício de seu trabalho na escola. $\mathrm{O}$ 
'cotidiano escolar' é definido por Candau (2003, p. 161) como um universo permeado pela "relação entre as culturas, atravessado por tensões e conflitos". O coordenador pedagógico, imerso nesta trama de relações, busca criar uma rotina de trabalho na escola. Nas falas, os entrevistados relatam os desafios enfrentados durante o percurso do dia a dia na escola.

Aqui na escola nós colocamos muito em prática. A gestão é uma gestão pedagógica,
mas, ela deixa muito à vontade a coordenação para exercer o seu papel. Então é
importante que a escola deixe o coordenador praticando a sua função, que é esse elo
entre o fazer e o acontecer. Não ficar desviando os papéis porque quando você vai
ver no final do dia, muitas vezes, em muitas escolas, quando você vai fazer a
avaliação do seu dia, você vai ver que no pedagógico você praticamente não fez
nada. E aqui na escola eu tenho essa liberdade do meu dia ser destinado a dedicar
praticamente cem por cento ao pedagógico (coordenadora Aline ${ }^{4}, 2009$ ).

A coordenadora Aline conceitua o seu cotidiano como o "fazer e o acontecer" e faz críticas às escolas que desviam o coordenador de sua função, quando ela diz: "não ficar desviando os papéis". Ela analisa este "desvio de papéis" como nocivo ao trabalho pedagógico. O coordenador considera que o "desvio de papéis" prejudica o desempenho de sua função pedagógica na escola, que deve estar em consonância com as atribuições definidas pela Circular No 37 (RIO DE JANEIRO, 1998b).

Eu acho que poderia ter um tempo maior para fazer realmente o pedagógico (coordenadora Elza, 2009).

O meu sonho na coordenação seria poder trabalhar na coordenação mesmo, ficar só no pedagógico (coordenadora Shana, 2009).

A gente faz o trabalho de assistente social, além do trabalho da coordenação (coordenadora Kátia, 2009).

Os coordenadores revelaram que executam muitas tarefas que não fazem parte de suas atribuições, porém eles as consideram necessárias para manter a organização escolar. Podemos perceber a diversidade de tarefas que eles executam durante o cotidiano e que são distanciadas de suas atribuições, como o exemplo citado por Kátia: “assistente social”.

A sobrecarga do trabalho, causada pela falta de pessoal, traz como consequência a redistribuição das tarefas sobre os gestores escolares. A coordenadora Solange define bem o que acontece em sua escola:

A falta de estrutura é que atrapalha o trabalho, a falta de pessoal. Essa falta de
professor mexeu no meu trabalho, mexeu no trabalho da sala de leitura, e no
trabalho da diretora-adjunta que também está pegando a turma, e complica tudo,
atrasa tudo, a gente tem que trabalhar mais horas para poder dar conta dos "dois
recados". Este ano, destes dez anos que eu estou na função, é a primeira vez que eu
não entro em turma para substituir professor, eu só tenho uma matrícula, eu estou

\footnotetext{
${ }^{4}$ Os nomes citados neste artigo são fictícios, respeitando, de acordo com a ética da pesquisa, o anonimato dos informantes.

Momento: diálogos em educação, E-ISSN 2316-3100, v. 26, n. 1, p. 143-160, jan./jun. 2017
} 
cansada, exausta. Teve época de substituir professor por dois meses. Teve um ano que ficamos com quatro turmas sem professor, entrava eu, a diretora, a diretoraadjunta, todas nós com uma matrícula. Este ano, eu disse: "não vou entrar porque eu não estou aguentando" (coordenadora Solange, 2009).

Outros exemplos:

No momento eu estou sobrecarregada. Passamos sem diretor-adjunto alguns meses então, eu dou apoio à diretora. Não dá para ficar sem um diretor-adjunto numa escola deste tamanho (coordenadora Elena, 2009).

(...) a minha diretora está licenciada por motivo de saúde, e nós somos seres humanos, podemos ficar doentes. Quando tem pessoal faltando na escola, eu não posso fechar a minha porta e fingir que nada está acontecendo (...) (coordenadora Shana, 2009).

Solange define a "falta de estrutura" como sinônimo de "falta de pessoal". $\mathrm{Na}$ realidade, a falta de professor na rede obriga aos docentes da equipe técnico-pedagógica a assumirem também a função de regentes de turma, sem deixar de executar as obrigações e compromissos concernentes aos seus respectivos cargos. A sobrecarga de trabalho que, consequentemente recai sobre estes profissionais gera cansaço e desânimo em relação ao desempenho de suas funções. Nos relatos de Elena e Shana, a falta de pessoal recaiu sobre a própria equipe gestora onde as funções burocráticas inerentes do diretor ou diretor-adjunto recaíram também sobre o coordenador pedagógico. As entrevistadas assumem tarefas que não fazem parte de suas atribuições por se sentirem compromissadas afetivamente com a equipe e com o andamento da organização, onde acabam assumindo as responsabilidades como suas.

Tardif e Lessard (2007) definem "trabalho docente" como aquele que é exercido por pessoas e para pessoas, as quais, eles denominam "matéria prima do processo do trabalho interativo" foco da ação direta do professor. Estas relações de trabalho implicam num conjunto de mediações linguísticas e simbólicas exercidas entre os atores (coordenador pedagógico e os membros da comunidade escolar: professores, alunos, responsáveis, direção), exigindo destes docentes, melhores qualificações escolares que requeiram conhecimentos abstratos.

O trabalho cotidiano na escola também envolve relações sociais presentes no trabalho com o "objeto humano, somando-se à linguagem simbólica, a afetividade, a ética, o controle, e os meios que são os conhecimentos e a cultura" (TARDIF E LESSARD, 2007, p.31). Nas entrevistas, os coordenadores trouxeram suas definições do que consideram como "trabalho" no cotidiano da escola. 


\begin{abstract}
Vão surgindo muitas coisas no meu caminho. Eu sento em minha mesa e já tem três ou quatro recados importantes da $\mathrm{CRE}^{5}$ ou da Secretaria (Municipal de Educação) que eu tenho que dar conta, quadros ${ }^{6}$ que eu devo estar olhando ou estar fazendo; então eu lembro que daqui a dois ou três dias é o meu "Centro de Estudos" e eu já combinei que vou trabalhar isso ou aquilo com o professor. E então eu vou ver que material eu vou utilizar, que textos eu vou ler, aparece criança machucada e eu corro para atender, igual agora quando você chegou (referindo-se à pesquisadora) tinha uma criança que urinou nas calças, e eu paro para procurar uma roupa limpa, eu paro, sento no computador, abro e-mails, atendo o telefone, às vezes tem reunião no meio do dia, eu saio, vou à reunião, volto. E quando acabou o dia eu tenho a impressão de que eu não fiz nada (coordenadora Elisa, 2009).
\end{abstract}

Quando a coordenadora Elisa comenta: "acabou o dia eu tenho a impressão de que eu não fiz nada", revela as demandas que o coordenador tem de "dar conta" no decorrer do cotidiano escolar, das emergências que exigem solução imediata. O cotidiano da escola, especificamente no cotidiano de trabalho do coordenador, envolve atividades não previstas, mostrando que o trabalho escolar demanda a presença de profissionais que possam adaptar-se com rapidez às inesperadas mudanças na rotina da escola. Comparando o cotidiano do coordenador pedagógico com o do professor, percebe-se que este possui um caráter mais flexível, repleto de atividades não previstas, diversas das atribuições de sua função, mas que acabam sendo assumidas por ele, devido ao seu compromisso com a organização da escola.

Almeida (2005) afirma que a rotina de trabalho do coordenador pedagógico é permeada pelo diálogo presente nas relações estabelecidas no cotidiano da escola, tanto da comunidade escolar, quanto da Coordenadoria Regional de Educação (CRE) e Secretaria Municipal de Educação (SME), caracterizados por diálogos "horizontais" e "verticais". Na escola, esse profissional se torna o "catalisador" dos problemas e dos conflitos existentes entre os diferentes segmentos da comunidade escolar, compartilha suas responsabilidades e atende as demandas da escola. Ele acaba assumindo diferentes papéis, sentindo-se sobrecarregado com tantas responsabilidades, gerando um sentimento de solidão. Esse fato pode ser observado nas falas a seguir:

Eu entro na escola e o tempo todo eu sou solicitada (coordenadora Rosana, 2009).

Passo até o final do dia atendendo responsáveis, vendo criança, é isso (coordenadora Aline, 2009).

\footnotetext{
${ }^{5}$ CRE - Coordenadoria Regional de Educação: trata de efetuar a comunicação local entre as deliberações da Secretaria Municipal de Educação (SME) às escolas referentes à sua região, exercendo também função fiscalizadora. A estrutura de acompanhamento da SME na Cidade do Rio de Janeiro, atualmente, é dividia em onze (11) CREs, localizadas em pontos estratégicos da cidade.

${ }^{6}$ Quadros de desempenho escolar ou de quantitativo de alunos e de turmas que são entregues periodicamente a CRE, a pedido da SME a fim de acompanhar o desempenho dos alunos e o trabalho desenvolvido nas escolas municipais da Cidade do Rio de Janeiro.

Momento: diálogos em educação, E-ISSN 2316-3100, v. 26, n. 1, p. 143-160, jan./jun. 2017
} 
É aquela que faz tudo: que ajuda ao professor, que ajuda ao aluno, que orienta o responsável. É um "ponto de equilíbrio", é uma pessoa realmente, que ajuda as pessoas que trabalham na escola, a comunidade escolar (coordenadora Elza, 2009).

A falta de estrutura é o que atrapalha o meu trabalho, a falta de pessoal. Essa falta de professor mexeu no meu trabalho, mexeu na sala de leitura e no trabalho da diretora-adjunta que também está pegando turma e complica tudo, atrasa tudo. A gente tem que trabalhar mais horas para poder dar conta dos "dois recados" (coordenadora Solange, 2009).

A falta de professores e funcionários traz como consequência a sobrecarga de trabalho para o coordenador pedagógico gerando a "falta de rotina" associada à improvisação, trazendo "mal-estar" no exercício de suas atividades cotidianas. Os coordenadores pedagógicos identificam no decorrer do cotidiano de trabalho dificuldades e enfrentamentos em suas relações com os diversos segmentos existentes na escola. Eles definem sua atuação cotidiana como: "o tempo todo eu sou solicitada"; "circulando dentro da escola", "aquela que faz tudo" e os desafios enfrentados como: "as coisas que surgem no caminho".

Exemplos descritos sobre o trabalho na escola:

Entrei. Vou pegar minha chave, já tem alguém (um professor) me dizendo assim: "olha, você atende uma mãe, porque eu preciso levar a minha turma para a sala", eu atendo (...) E a outra vem: "Preciso de material." Tem o material que se distribui para o professor. Se está tendo problema na hora do recreio, eu vou também. Vou lá falar com o professor de Educação Física, porque eu queria que ele fizesse um trabalho diferente com alguma turma. Até eu abrir a porta da minha sala já tem mil coisas para fazer, até eu chegar a abrir a porta e trazer a minha bolsa para cá já aconteceram várias coisas (...) Eu entro na escola e o tempo todo sou solicitada. (...) Não tem rotina. É assim: eu chego, e me programo para fazer determinadas coisas, e não consigo de jeito nenhum fazer aquilo, porque toda hora vem um aluno para conversar comigo, outro aprontou dentro de sala e o professor traz para mim, é o professor que chega para pedir alguma coisa, é o telefone que toca, é o diretor que está em reunião, então eu tenho que ficar dando suporte à outra (diretora-adjunta) que fica na secretaria, é falta de funcionário, é licença de professor e eu tenho que entrar em sala (dar aula no lugar da professora). Estamos com falta de um professor, então é a professora de sala de leitura que está em turma, e eu tenho que largar o meu trabalho para o trabalho da sala de leitura não parar, quer dizer, não dá para ter rotina, é uma criança que se machuca, e a gente tem que ver, isto é, não consigo ter rotina. Por mais que eu tente fazer o meu planejamento, eu não consigo. Se eu quiser marcar uma reunião com a direção, não tenho um espaço físico que se distancia das salas de aula. E se acontece algum problema com as professoras eu tenho que ir para sala com elas, então não tem rotina, não dá para ter (coordenadora Solange, 2009).

Se você me pegar aqui sentada é muito difícil, só se eu estiver com o meu caderninho de leitura ou presa no centro de estudos. Fora disso é circulando. Eu entro na escola, eu costumo circular (...) eu circulo nas turmas para ver se tudo está bem eu vejo se os professores estão precisando de alguma coisa (...) eu não vou parar, é circulando o tempo todo (coordenadora Elena, 2009).

Descrever um dia (...) são todos diferentes (...) atender a algum responsável que já estiver marcado ou mesmo que não tenha marcado, resolver briga de aluno, socorrer as professoras quando elas estão com alguma dúvida na aula ou uma criança com dificuldades, basicamente é isso (coordenadora Zélia, 2009). 
Vão surgindo coisas no meu caminho (...) aparece criança machucada e eu corro para atender, uma criança que urinou nas calças e eu paro para procurar uma roupa limpa (...) abro e-mails, atendo telefone (...) ou seja: um eterno corre-corre, é muito dinâmico, é uma "roda viva", eu não paro (coordenadora Elisa, 2009).

A predominância das situações não previstas, existentes no cotidiano do coordenador pedagógico, demonstra que ele passa a ter dificuldades em planejar sua rotina de trabalho. Eles relatam que fazem o planejamento de tarefas, mas, não conseguem cumpri-lo, causando uma sensação de incapacidade ou inaptidão para o exercício da função e assumem a responsabilidade pelo não-cumprimento de seu planejamento ou pelo desvio das tarefas inerentes à sua função que são deixadas de lado por causa das emergências que surgem no cotidiano escolar. A expressão mais evidente que descreve sucintamente estas situações adversas é definida por eles como: "não tem rotina", que somam-se a exemplos como: "descrever um dia (...) são todos diferentes", "vão surgindo coisas no meu caminho". As situações inesperadas são resolvidas no desenrolar do dia, caracterizando o coordenador pedagógico como um "apagador de incêndio" (ALMEIDA, 2005, p.33).

Conflitos surgem, necessidades emergem, e também se percebe como a Coordenadoria Regional de Educação (CRE) ou a Secretaria Municipal de Educação (SME) interferem no planejamento cotidiano dos coordenadores pedagógicos, conforme a coordenadora Elisa relata: "Eu sento em minha mesa e já tem três ou quatro recados importantes da CRE ou da Secretaria (SME) que eu tenho que dar conta".

Outra interferência externa percebida no cotidiano de trabalho do coordenador pedagógico é o comparecimento do responsável sem prévio agendamento, conforme a coordenadora Rosana comenta: "a mãe vem aqui e eu atendo". Os alunos que sofrem acidente ou se envolvem em conflitos, interferem no trabalho do coordenador pedagógico, conforme podemos observar na fala da coordenadora Elisa: "aparece criança machucada e eu corro para atender". Os relatos dos entrevistados confirmam que o cotidiano do coordenador pedagógico é cheio de imprevistos e atividades não planejadas que exigem resolução urgente, resultante também da falta de pessoal na escola. O estabelecimento de um cotidiano planejado pelo coordenador pedagógico é dificultado pelas emergências, algumas já estudadas, porém, vale a pena retornar algumas questões e levantar outras. O planejamento do trabalho nem sempre é executado devidamente, conforme os exemplos que seguem.

O meu dia oficialmente começa às sete horas, mas as coisas vão acontecendo desde o momento que eu chego à escola (...). Como eu vou descrever o meu dia? Eu não Momento: diálogos em educação, E-ISSN 2316-3100, v. 26, n. 1, p. 143-160, jan./jun. 2017 
sei como descrever. Eu procuro trabalhar de forma dinâmica, rápida e com qualidade (...). E no dia a dia (...). Seu eu for colocar no papel tudo o que eu faço, eu acabo fazendo tudo (coordenador João, 2009).

É difícil! Difícil mesmo, até porque a gente faz tanta coisa na escola, o que posso dizer sobre o que faço diariamente, fica complicado (coordenadora Elza, 2009).

Podemos perceber que o cotidiano do coordenador pedagógico dificilmente é voltado para o cumprimento de um planejamento de ações pedagógicas cotidianas ou para a execução de tarefas de sua exclusiva atribuição. As emergências que são as situações não previstas no planejamento de atividades do coordenador acabam atropelando sua rotina. Mas, há casos em que os coordenadores entrevistados afirmaram ter um planejamento e que conseguem cumprilo devidamente no decorrer de seus cotidianos. As justificativas são voltadas para a composição dos recursos humanos das escolas ou do apoio que recebem de seus diretores.

O meu trabalho é muito facilitado pelos anos que eu já estou aqui. A escola já está organizada. O grupo não teve muita mudança (...). Eu acho que aqui facilita nisso (coordenadora Flávia, 2009).

O meu trabalho aqui, graças a Deus, é focado diretamente no pedagógico (...) eu e a direção temos uma simbiose maravilhosa. Então eu tenho muita liberdade no meu fazer (coordenadora Elisa, 2009).

Ela (a diretora) deixa muito à vontade a coordenação para exercer o seu papel (...) Aqui na escola eu tenho essa liberdade do meu dia ser destinado dedicar praticamente cem por cento ao pedagógico (coordenadora Aline, 2009).

A fala da coordenadora Elisa é conflituosa, pois, ao mesmo tempo em que ela, no extrato anterior demonstra que o seu trabalho é voltado exclusivamente para o pedagógico, em outro momento da entrevista, ela expõe sua dificuldade em estabelecer uma rotina no decorrer de seu cotidiano a fim de cumprir o seu planejamento, pois, ela mesma afirma: "vão surgindo muitas coisas no meu caminho". A fala conflituosa demonstra a predisposição da coordenadora em cumprir com o planejamento de sua rotina de trabalho, porém, ao mesmo tempo, ela é desafiada a buscar soluções para problemas emergentes.

De acordo com TARDIF e LESSARD (2007), o cotidiano de trabalho na escola é interpretado pela repetição de atividades uniformes. Eles denominam a rotina de trabalho na escola como "ciclos", isto é, o cotidiano é cíclico: a cada dia os ritos são repetidos pelos professores e o coordenador pedagógico posiciona-se no papel do profissional que tem a função de garantir que este cotidiano seja cumprido. A entrada na escola permanece igual com tempos fixados pelo planejamento do calendário escolar que estabelece os horários de entrada na escola, do recreio, do encontro com os colegas e atividades pedagógicas previamente estabelecidas. A cada ano letivo, novos cotidianos são renovados de forma a manter a organização da escola. No caso dos coordenadores pedagógicos, as demandas que surgem Momento: diálogos em educação, E-ISSN 2316-3100, v. 26, n. 1, p. 143-160, jan./jun. 2017 
fora da sala de aula fazem com que os entrevistados percebam como "quebra da rotina" todos os imprevistos que acontecem no decorrer de seu cotidiano de trabalho.

Os coordenadores pedagógicos testemunham a vivência cotidiana dos professores, pois, partilham o mesmo espaço de trabalho e buscam juntamente com os docentes resolver os desafios provenientes do cotidiano escolar. Devido à flexibilidade de suas atribuições, inclusive por serem responsáveis pela formação continuada de professores, eles necessitam de constante formação para elaborarem atividades que respondam às demandas vindas de professores. A coordenadora Rosana desabafa: "conseguir um tempo para mim é muito raro", isto é, o tempo que ela considera necessário para preparar um estudo para os professores ou ler um texto pedagógico, ou elaborar o planejamento de atividades concernentes ao desenvolvimento de seu trabalho, desloca-se para a satisfação das necessidades imediatas da comunidade escolar, contrariando o que Tardif e Lessard expõem abaixo;

\footnotetext{
Depois da chegada da escola, normalmente segue-se um período em que os professores preparam sua jornada de trabalho. Além disso, boa parte das pausas e dos períodos de disponibilidade são dedicadas às atividades de preparação. A análise do nosso material indica que a preparação corresponde a atividades tais como estas: preparar os centros de atividades e prever o material pedagógico necessário; (...) reproduzir os textos; (...) responder a um telefonema de um pai; lembrar aos colegas sobre uma reunião; rever as lições do dia, etc. (2007, p.174).
}

Os coordenadores demonstram que, no decorrer do tempo que estão na escola, ficam restritos a resolver problemas emergentes do cotidiano escolar. No caso do planejamento das atividades, inclusive dos "centros de estudos", não ficou claro se eles utilizavam o tempo de trabalho disponível na escola ou se planejavam as atividades a serem realizadas em sua rotina de trabalho em casa.

A pesquisa realizada em 2015 buscou conhecer o cotidiano de trabalho do coordenador pedagógico verificando se havia semelhanças ou contrastes com os dados levantados e analisados em 2009. Pudemos verificar nuances e permanências entre os desafios enfrentados pelos coordenadores entrevistados em 2009 e os sujeitos pesquisados em 2015.

É complicado porque eu me programo, tenho uma proposta para cada dia (...), mas, surgem tantas situações nesse meio tempo que de repente eu me vejo fazendo coisas completamente diferentes daquilo que programei (coordenadora Selma, 2015).

(...) a rotina não existe. (coordenadora Sarah, 2015).

São coisas que vão acontecendo que a gente tem que ir sanando, direcionando (...). (coordenadora Tatiana, 2015). 
Percebemos nos relatos dos coordenadores entrevistados durante a pesquisa realizada em 2015 que ainda existem muitos desafios encontrados na primeira pesquisa realizada em 2009, citamos como exemplos: "não tem rotina"; "as coisas que vão acontecendo que a gente tem que ir sanando, direcionando"; "me vejo fazendo coisas completamente diferentes daquilo que programei”. Estas falas retratam que o coordenador pedagógico continua enfrentando os mesmos desafios relatados pelos entrevistados da pesquisa realizada em 2009, juntamente com questões que permanecem: a dificuldade de cumprir o planejamento de seu cotidiano, a sobrecarga de trabalho, a falta de infraestrutura no espaço escolar.

Os relatos dos entrevistados, na pesquisa mais recente, revelam que os coordenadores pedagógicos passaram a priorizar novas tarefas de acordo com as demandas vindas das novas diretrizes políticas da SME, mais voltadas para a planificação curricular e para o desempenho dos alunos em provas padronizadas (MARCONDES, LEITE; OLIVEIRA, 2012). Estas atividades são voltadas para um aspecto mais regulador do cotidiano do coordenador pedagógico, descrito como a verificação de documentos preenchidos pelos professores. Tomamos como exemplos destes documentos: diários de classe, relatórios, planejamentos, etc., tornando o coordenador pedagógico um "controlador e regulador do trabalho dos professores" (MARCONDES; LEITE; OLIVEIRA, 2012, p. 27). Vemos como exemplo os relatos a seguir:

$\mathrm{Eu}$ fico olhando os planejamentos, avaliando esses planejamentos, vendo que não é "bem aquilo" (coordenadora Selma, 2015).

No meu cotidiano de trabalho eu reservo uma hora para olhar os cadernos dos professores, os diários de classe (...) eu ainda olho os diários, verifico se as atividades são feitas (coordenadora Samantha, 2015).

A ação reguladora presente no cotidiano do coordenador pedagógico demonstra que ele busca adequar às práticas docentes cotidianas às demandas exigidas pela SME. $\mathrm{O}$ coordenador fiscaliza o trabalho docente e verifica se os materiais curriculares enviados pela SME às escolas são realmente utilizados em sala de aula. A coordenadora Samantha, entrevistada em 2015, justifica sua ação reguladora sobre o trabalho docente afirmando que ela "procura fazer com que elas (as professoras) melhorem na sala de aula".

Ball (2005, p.545) afirma que o "gerencialismo" modifica o comportamento cotidiano de trabalho de gestores e professores nos espaços escolares, de acordo com as novas políticas que interferem neste cotidiano, através de indicadores legais. Estes indicadores compreendem 
todos os documentos provenientes da SME, enviados às escolas com ênfase no cumprimento imediato. O gerencialismo se revela por meio de avaliações por desempenho onde o controle se concretiza em ações de fiscalização e verificação constante do trabalho docente, fortalecendo as relações hierárquicas e verticais entre SME e escolas; gestores, coordenadores e professores, incutindo nos cotidianos de docentes e gestores, as rotinas performáticas.

Percebemos que os coordenadores entrevistados em 2015 ainda enfrentam, de acordo com os seus relatos, desafios de situações inesperadas que surgem no decorrer do cotidiano escolar, assim como os sujeitos pesquisados em 2009. Porém, a pesquisa de 2015 revelou que novas tarefas foram adicionadas às já existentes no conjunto de atribuições inerentes ao coordenador pedagógico, tal como o papel de regulador do trabalho pedagógico dos professores. As novas tarefas modificaram as "ritualidades" do coordenador pedagógico trazendo novas responsabilidades e atribuições que se somam às já existentes.

\section{CONSIDERAÇÕES FINAIS}

Trabalhamos neste texto com o conceito de cotidiano subjetivo, onde retratamos o cotidiano escolar dos coordenadores pedagógicos entrevistados através dos relatos de suas atividades realizadas no decorrer de seus trabalhos nas escolas. Remetemo-nos a PAIS (2003) para compreender o cotidiano como o conjunto de "ritualidades" que fazem parte do dia a dia dos coordenadores no espaço escolar.

A entrevista semiestruturada, sob a forma de conversa informal, nos possibilitou visualizar a "rotina" dos coordenadores pedagógicos. Para isso, utilizamos o conceito do "cotidiano subjetivo" (PAIS, 2003) considerando que os relatos são fruto de memórias, vivências, experiências de vida reveladas nas falas dos entrevistados.

Percebemos que nas duas pesquisas, realizadas em dois momentos diferenciados das políticas educacionais predominantes na Cidade do Rio de Janeiro (OLIVEIRA, 2009; 2015), no cotidiano escolar do coordenador pedagógico permanecem a falta de pessoal na escola, a sobrecarga de trabalho resultante das demandas vindas da SME, e os desafios cotidianos resultantes dos enfrentamentos do coordenador vindos das "emergências que surgem".

Os coordenadores sentem-se sobrecarregados por não conseguirem cumprir com os seus planos de trabalho diante da constante "falta de rotina" da escola. Muitas vezes eles assumem tarefas que não fazem parte de suas atribuições, mas, assumem a responsabilidade 
de cumpri-las a fim de manter a organização escolar em funcionamento, muitas vezes, deixando as atividades que lhes são inerentes para um segundo plano.

Novamente nos voltamos para as questões levantadas neste texto: O que é entendido como cotidiano escolar no entendimento do coordenador pedagógico? O cotidiano escolar para o coordenador pedagógico compreende as rotinas de trabalho que ele exerce na escola tanto as tarefas que ele desempenha e que fazem parte de suas atribuições como aquelas que ele realiza porque necessita substituir a falta de pessoal na escola. $\mathrm{O}$ coordenador assume responsabilidades que fazem parte da organização escolar, e quando falta algum professor ou funcionário, assume as tarefas que seriam atribuídas ao profissional que faltou, a fim de zelar pela organização escolar. Os coordenadores pedagógicos sentem-se sobrecarregados e acham que "não fizeram nada" porque o seu cotidiano de trabalho foi absorvido pelas tarefas emergentes, não previstas em seu planejamento.

Quais são os desafios que o coordenador encontra em seu trabalho cotidiano? O coordenador pedagógico enfrenta muitos desafios: substituir professor faltoso, assumir a função de secretário escolar, quando é necessário, preencher documentos, prestar socorro a crianças machucadas e outras atividades emergentes que surgem na escola, que eles definem como: "vão surgindo coisas no meu caminho". Percebemos que o cotidiano do coordenador é repleto de situações que podemos denominar de "inesperadas" porque é o resultado das "ritualidades" não planejadas, que exigem uma resolução imediata. O cotidiano do coordenador pedagógico se resume em realizar tarefas de planejamento concomitante a atividades não planejadas e muitas vezes estranhas às suas atribuições e responsabilidades. Portanto, as "ritualidades" neste contexto são definidas como o conjunto de situações esperadas e inesperadas que fazem parte dos desafios existentes no cotidiano da escola.

Os fatores preponderantes que interferem no cotidiano do coordenador pedagógico são: a falta de infraestrutura, a falta de pessoal, a falta de recursos materiais, a interferência externa da SME. Todas essas situações sobrecarregam o coordenador pedagógico de atividades que ele "tem que dar conta". Eles buscam cumprir todas as demandas exigidas no cotidiano escolar para contribuir para o funcionamento da organização escolar.

$\mathrm{Na}$ pesquisa de 2015, percebemos que novas atribuições foram acrescidas ao já sobrecarregado cotidiano do coordenador. Ele deve "acompanhar as atividades docentes", 
"olhar os planejamentos" e "avaliar os planejamentos", somando-se às demais tarefas que o coordenador pedagógico já executava no decorrer de suas "ritualidades".

Verificamos que há necessidade de possibilitar aos coordenadores pedagógicos uma infraestrutura adequada de trabalho, tanto física, no que se refere às condições do prédio escolar e de funcionamento de seus equipamentos, quanto de recursos humanos. Assim, o coordenador pedagógico poderá estar livre para praticar as "ritualidades" inerentes às suas atribuições. Os coordenadores entrevistados percebem que o seu trabalho é importante para a organização escolar porque eles se envolvem com todos os acontecimentos esperados e inesperados que surgem no espaço escolar, assumindo-os como de sua natural responsabilidade.

\section{REFERENCIAS}

ALMEIDA, L. R. Um dia na vida de um coordenador pedagógico de escola pública. In:_ ; PLACCO, V. M. N. S. (Org.). O coordenador pedagógico e o cotidiano da escola. 3 ed. São Paulo; Loyola, c. 2, 21-46p., 2005.

ALVES, N.Cultura e cotidiano escolar. Revista Brasileira de Educação. Rio de Janeiro, Associação Nacional de Pós-Graduação e Pesquisa em Educação (ANPED), ano 4, n.23, 6274p., mai-ago, 2003.

ANDRÉ, M.E.D.A. Etnografia da prática escolar. 10ed. Campinas, Papirus, 2003.

BALL, S. J. Profissionalismo, gerencialismo e performatividade. Cadernos de pesquisa. São Paulo, Fundação Carlos Chagas, v.35, n.126, 539-564p., set-dez 2005.

BRASIL. Lei $\mathrm{n}^{\mathrm{o}} 9394$ de 20 de dezembro de 1996. Disponível em: <http://www.planalto.gov.br/ccivil_03/LEIS/19394.htm> Acesso em: 10 abr. 2009.

BRASIL. Índice de Desenvolvimento da Educação Básica. Ministério da Educação. Disponível em: <http://portal.mec.gov.br/index.php> Acesso em: 25/08/2012.

CANDAU, V.M.F. Reformas educacionais hoje na América Latina. In: MOREIRA, A.F.B. Currículo: políticas e práticas. 7 ed. São Paulo, Papirus, c.2, 29-42p., 2003.

DUARTE, R. Entrevistas em pesquisas qualitativas. Revista Educar. Curitiba, Editora da Universidade Federal do Paraná (UFPR), n.24, 213-225p., 2004.

MARCONDES, M.I.; LEITE, V.F.; OLIVEIRA, A.P. Reforma e recontextualização das políticas: o papel dos coordenadores pedagógicos nas escolas municipais do Rio de Janeiro. Revista Diálogo Educacional. Rio de Janeiro, Fundação Carlos Chagas. Ano 12, n. 35, 187209p., 2012.

OLIVEIRA, E; ENS, R.T.; FREIRE ANDRADE, D.B.S.; MUSSIS, C.R. A análise de conteúdo na produção do conhecimento. Revista Diálogo Educacional. Curitiba, Universidade Federal do Paraná, v.4, n.9, 11-27p., maio-ago 2003. 
OLIVEIRA, I.A.; FONSECA, M.J.C.F.; SANTOS, T.R.L. A entrevista na pesquisa educacional. In: MARCONDES, M.I.; TEIXEIRA, E.; OLIVEIRA, I.A. (Orgs.) Metodologia e técnicas de pesquisa em educação. Belém, Universidade do Estado do Pará, c.3; 37-53p., 2010.

PAIS, J.M. Vida cotidiana: enigmas e revelações. São Paulo, Cortez, 2003.

RIO DE JANEIRO. Lei 2.619 de 16 de janeiro de 1998. Dispõe sobre a estrutura organizacional, pedagógica e administrativa da rede pública municipal de educação. Diário Oficial do Rio, Rio de Janeiro, ano 11, n. 210, 4-5p., 19 jan 1998a.

Secretaria Municipal de Educação. Departamento Geral de Educação. Circular E/DGED no 37: Atribuições dos coordenadores pedagógicos de 13 de julho de 1998b. In: Curso para docentes do ensino fundamental - coordenador pedagógico. Rio de Janeiro: Fundação João Goulart - Prefeitura da Cidade do Rio de Janeiro, 8-9p., 2005 (circulação interna).

SACRISTÁN, J. G. Consciência e acção sobre a prática como libertação profissional dos professores. In: NÓVOA, A. (Org.). Profissão professor. v. 3, 2ed. Lisboa: Porto editora, c. 3, 63-92p., 1999.

TARDIF, M.; LESSARD, C. O trabalho docente: elementos para uma teoria da docência como profissão de interações humanas. 3 ed. Petrópolis: Vozes, 2007. 